\title{
URBAN MORPHOLOGICAL DYNAMICS IN SANTIAGO (CHILE): PROPOSING SUSTAINABLE INDICATORS FROM REMOTE SENSING
}

\author{
H.J. Hernández ${ }^{\text {a*}}$, M.A. Gutiérrez ${ }^{\text {a }}$ \& M.P. Acuña ${ }^{a}$ \\ ${ }^{a}$ Geomatics and Landscape Ecology Lab, Forestry and Nature Conservation Faculty, Santa Rosa 11315, Santiago, Chile - \\ jhernand@uchile.cl, paz.acuna.ruz@gmail.com
}

Commission VIII, WG VIII/8

KEY WORDS: Urban structure type, V-I-S model, spectral unmixing, sustainable indicators

\begin{abstract}
:
Latin America is one of the world's most urbanised regions, with more than $80 \%$ of inhabitants living in urban areas and over 50 cities with at least 1 million inhabitants. The concept of urban structure types (UST) allows the dynamics of a growing urban environment to be captured in its quantity and quality. They are defined as areas of homogenous appearance in the urban matrix with a recognisable mixture of built-up areas and open spaces. We used the vegetation-impervious-soil (V-I-S) model approach to classify and monitor different types of USTs in Santiago $(\sim 800 \mathrm{~km} 2)$, Chile between 1985 and 2015. The V-I-S model is based on a simplification of the large diversity of urban land cover types in three general categories: vegetation, impervious surfaces and soil. These categories were obtained by processing Landsat-5 TM and Landsat-8 OLI images. First, we applied standard radiometric calibration and co-registration methods to all datasets. Second, using a linear spectral unmixing algorithm we performed a soft classification of urban land cover types (end members): trees, shrubs, herbaceous plants, soils, buildings, roads and water bodies. All end members were validated using a combination of photointerpretation on high-resolution images $(\sim 1 \mathrm{~m})$ and field data collection (only for 2015). In each pixel we used the resulting probability scores, logically grouped, to obtain final values for each V-I-S component. Third, we used statistical clustering of V-I-S values to create a set of eight pixel groups, which we interpreted as USTs and mapped them for each date. The overall accuracy for V-I-S components in 1985 and 2015 were $78 \%$ and $82 \%$, respectively, and errors did not exhibit any spatial correlation. The main sources of differentiation between USTs were the trade-off proportions between vegetation and impervious components, whereas soil proportions remained near $5 \%$ across the city in both dates. To analyse the change in UST spatial configuration between dates, we used a set of selected landscape metrics and discussed their use as indicators for sustainable urban development. These indicators relate to the dispersion pattern of urban growth, the connectivity of open green space and the complexity in the composition of the UST types within the different sectors of the city. We were able to identify, using the dynamics exhibited by the USTs, three main zones: (1) city centre, where USTs of high-intensity development predominate, (2) eastern high-income areas whose spatial structure is marked by a relatively high urbanisation intensity with a very large proportion of vegetated spaces, and (3) peripheral areas, with significant changes in composition and configuration of USTs, in recent decades, showing high rates of urbanisation, shifting from low-medium to high densities. We concluded that these patterns and their dynamics are mainly determined by the spatial socio-economic stratification of the population.
\end{abstract}

\section{INTRODUCTION}

Latin America is one of the world's most urbanised regions, with more than $80 \%$ of inhabitants living in urban areas and over 50 cities with at least 1 million inhabitants (United Nations, 2014). In the Latin American context Santiago de Chile appears as one of the cities where urban expansion has led to serious diseconomies and environmental problems with no real efforts being made towards a proper territorial planning policy (Peterman, 2006; Romero and Ordenes, 2004).

The city location within an environmental watershed (defined as a semi-closed system) gives endogenous traits to atmospheric, water, geomorphological and biogeographical flows (Romero et al, 2003). Many of the contamination problems are directly related to this situation. From the urban ecology point of view, the urban structure can be studied using its morphology. Some neighbours seem to be similar to others within the city.
The concept of urban structure types (UST) allows the dynamics of a growing urban environment to be captured in its quantity and quality. They are defined as areas of homogenous appearance in the urban matrix with a recognisable mixture of built-up areas and open spaces. In urban planning, the spatial typologies can help to structure data and provide an overview (Böhm, 1998).

From a remote sensing point of view, there are several approaches that can be used to assess USTs. Ridd (1995) proposed a vegetation-impervious-soil (V-I-S) model that can standardise the parametrisation of the urban environments and the actual definition of USTs within the city. The goal of this study was to identity Santiago's main USTs and assess their change between 1985 and 2015.

\footnotetext{
* Corresponding author
} 


\section{DATA AND METHODS}

\subsection{Study Area}

The study area was the whole extension of Santiago de Chile, about $800 \mathrm{~km}^{2}$ (Figure 1).

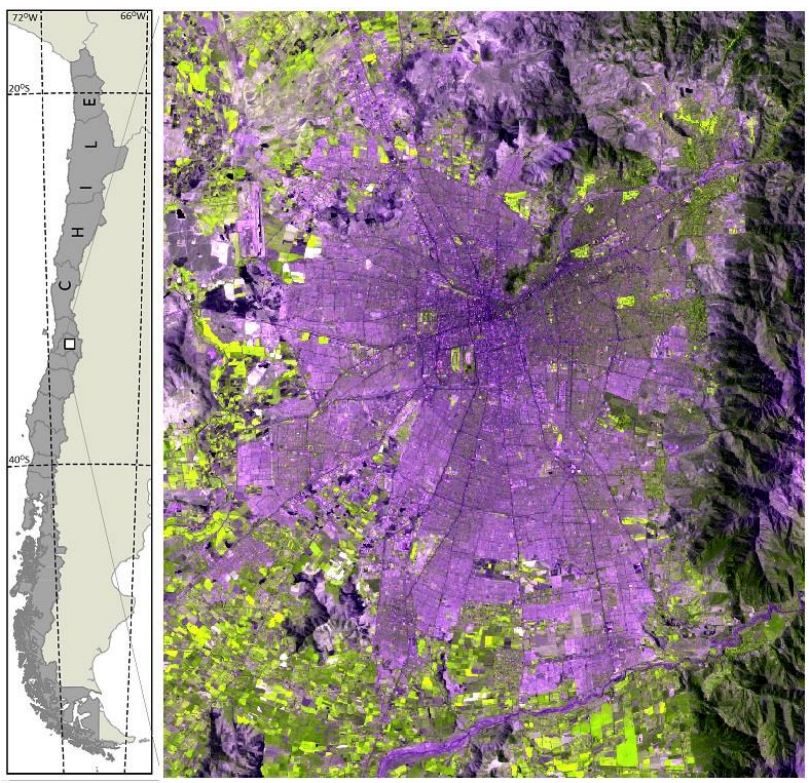

Figure 1. Study area: Santiago de Chile. Landsat-8 OLI image from January $28^{\text {th }} 2015$, RGB 753.

\subsection{Landsat Data and Processing}

We used one scene from Landsat-5 TM and a second one from Landsat-8 OLI (path 233 and row 83 in WRS-2), both taken in January (summer in the southern hemisphere). We used the V-I$\mathrm{S}$ model to classify and monitor different USTs in Santiago $(\sim 800 \mathrm{~km} 2)$, Chile between 1985 and 2015. The V-I-S model is based on a simplification of the large diversity of urban land cover types in three general categories: vegetation, impervious surfaces and soil. These categories were obtained by processing Landsat-5 TM and Landsat-8 OLI images.

First, we applied standard radiometric calibration and coregistration methods to all datasets. Second, using a linear spectral unmixing algorithm, we performed a soft classification of urban land cover types (end members): trees, shrubs, herbaceous plants, soils, buildings, roads and water bodies. All end members were validated using a combination of photointerpretation on high-resolution images $(\sim 1 \mathrm{~m})$ and field data collection (only for 2015).

In each pixel we used the resulting probability scores, logically grouped, to obtain final values for each V-I-S component (3 separated bands). Third, we used statistical clustering of V-I-S values to create a set of pixel groups, which we interpreted as USTs and mapped them for each date.

\section{RESULTS}

\subsection{Santiago Urban Structural Units}

The overall accuracy for the three V-I-S components (bands) in 1985 and 2015 were $78 \%$ and $82 \%$, respectively, and errors did not exhibit any spatial correlation. By using the three V-I-S bands we segmented the image into 8 types of USTs, 7 classified and 1 unclassified.

The final USTs are presented in Figure 2. It is important to note that the percentage share of each V-I-S component corresponds to an average value within each UST. The unclassified type (8) corresponds to sectors with misclassification, especially those related to soil components and therefore omitted from the analysis of urban structural units. The territorial expression of the USTs for each year of the study period unit is presented in Figure 3.

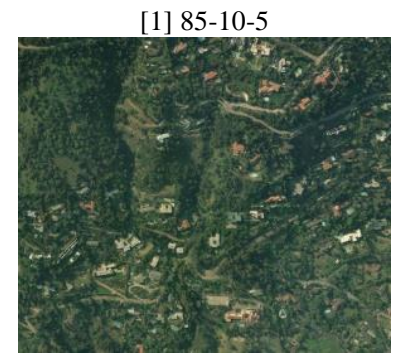

[3] 45-50-5

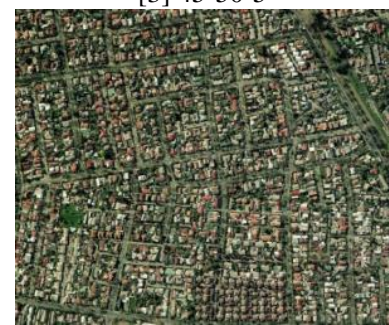

[5] 20-75-5

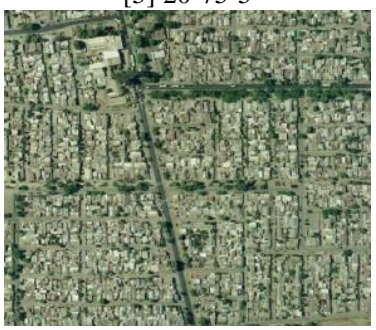

[7] $5-90-5$

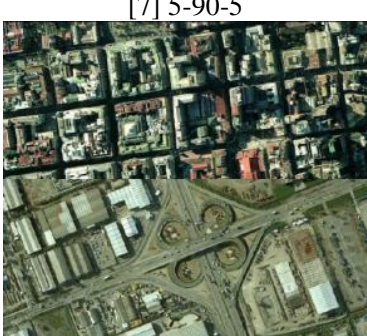

Figure 2. USTs for Santiago de Chile. [x]=indicates number of USTs and the three consecutive numbers indicate the percentage of the V-I-S components: V\% - I \% - S \%. Images are from Google Earth. 


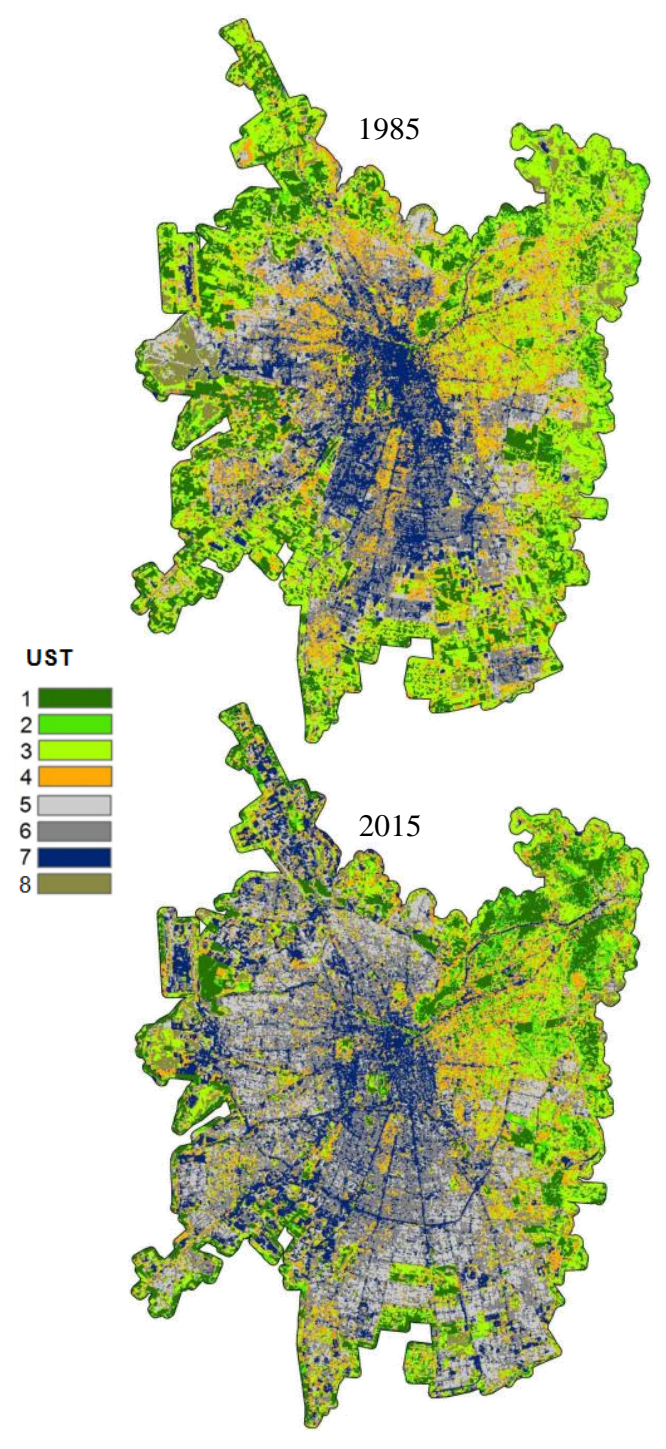

Figure 3. Urban Structural Units of Santiago in 1985 and 2015. USTs are described in Table 1. UST 8 corresponds to unclassified pixels.

\subsection{Change Analysis}

The main sources of differentiation between USTs were the trade-off proportions between vegetation and impervious components, whereas soil proportions remained near $5 \%$ across the city in both dates.

To analyse the change in UST spatial configurations between dates, we used a set of selected landscape metrics and discussed their use as indicators for sustainable urban development. These indicators relate to the dispersion pattern of urban growth, the connectivity of open green space and the complexity in the composition of the USTs within the different sectors of the city.

The first of the indices previously presented shows trends in composition and spatial configuration observed in each of the types of urban structural units, both in the city as a whole and in individual sectors. The percentage share of each type reveals that between 1985 and 2015 the types of units consolidated were the highly urbanised ones, i.e., UST 5 and 6, while UST7 remained virtually stable. Figure 4 presents an overall description of the changes in UST proportion during the study period.

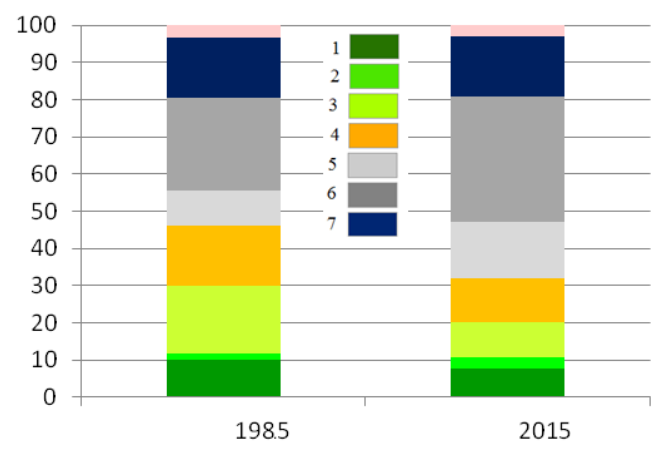

Figure 4. Percentage of each UST (colors) in the study area in 1985 and 2015.

Using the dynamics exhibited by the USTs we identified three main zones (see Figure 3): (1) city centre, where USTs of highintensity development predominate, (2) eastern high-income areas, whose spatial structure is marked by a relatively high urbanisation intensity with a very large proportion of vegetated spaces, and (3) peripheral areas, with significant changes in composition and configuration of USTs, in recent decades, showing high rates of urbanisation, shifting from low-medium to high densities. We concluded that these patterns and their dynamics are mainly determined by the spatial socio-economic stratification of the population.

\subsection{Useful indicators}

As can be seen in Figure 3, there are pixel groups belonging to the same class of UST. Thus, a set of patches of different sizes and shapes are formed matching the configuration of landscapes composed of a mosaic of patches defined by Urban et al. (1987). On this categorical raster, a set of landscape metrics can be derived to assess and monitor the urban spatial pattern and its change over time (Forman and Godron 1986). To select which metrics are best suited to this purpose, we first need to define the criteria they must fulfil. Based on the literature reviewed concerning the attributes that define a sustainable territorial urban model, three general criteria that can guide urban environmental planning Santiago from a spatial approach were outlined:

1. A rational use of soil resources, trying to control urban growth in a compact, graspable structure. An urban model with less dispersed and more compact growth is more sustainable. In this case, the built-area/inhabitant ratio is smaller and requires less maintenance (Rojas et al, 2011; Rueda, 1999).

2. Joint consideration of urban growth needs and the maintenance of natural values. An urban growth model integrated with the natural and rural environment that minimises the consumption of natural resources is more sustainable as it tends to not occupy lands with high ecological or agricultural values and maintains the connectivity of habitats, avoiding fragmentation (Rojas et al, 2011).

3. Complexity and mixed urban uses: there must be a mixture of land uses and development standards based on the 
community context. The aim is interdependence between social activities and ecological functions (Tyler and Perks 1998).

From the concurrence between the above criteria, the need for sustainable urban planning and the spatial processes analysed using spatial metrics in Santiago, we propose three groups of indicators (Table 1):

\begin{tabular}{|c|c|c|}
\hline $\mathrm{C}$ & Indicators & Goal \\
\hline 1 & $\begin{array}{l}\text { Level of UST dispersion by } \\
\text { class: } \\
\text { - Number of patches (NP) } \\
\text { - UST class area (CA) } \\
\text { - Nearest neighbour distance } \\
\text { (ENN) }\end{array}$ & $\begin{array}{l}\text { Higher concentration of } \\
\text { USTs with larger } \\
\text { proportions of } \\
\text { impervious surfaces at } \\
\text { the centre of the city. }\end{array}$ \\
\hline 2 & $\begin{array}{l}\text { Degree of UST fragmentation } \\
\text { with larger proportions of } \\
\text { vegetation : } \\
\text { - NP, AC and ENN } \\
\text { - Connectivity (GYRATE and } \\
\text { CONNECT) }\end{array}$ & $\begin{array}{l}\text { UST with larger } \\
\text { proportions of } \\
\text { vegetation should be } \\
\text { more compact, better } \\
\text { connected and evenly } \\
\text { distributed throughout } \\
\text { the city. }\end{array}$ \\
\hline 3 & $\begin{array}{l}\text { Degree of spatial intermixing of } \\
\text { different USTs: } \\
\text { - Interspersion (IJI) } \\
\text { - Contagion (CONTAG) } \\
\text { - Diversity (SHDI) }\end{array}$ & $\begin{array}{l}\text { Maximum intermixing } \\
\text { of different USTs. }\end{array}$ \\
\hline
\end{tabular}

Table 1: Proposed indicators for urban sustainable planning using the three selected criteria (C). Acronyms in capital letters in brackets indicate the name of the metric as used in FRAGSTATS (McGarigal et al., 2012).

The metrics that can be used are not limited to the list given in Table 1 . They should be revised according to local applicability in every focal urban landscape. In Table 2 , as an example, we present the net changes in the values of three selected metrics, percentage of participation in the landscape, number of patches and patch mean area in each UST.

\begin{tabular}{|c|c|c|c|c|c|c|c|}
\hline UST & $\mathbf{1}$ & $\mathbf{2}$ & $\mathbf{3}$ & $\mathbf{4}$ & $\mathbf{5}$ & $\mathbf{6}$ & $\mathbf{7}$ \\
\hline$\%$ & -3 & +1 & -9 & -5 & +5 & +10 & $\sim 0$ \\
\hline $\mathrm{NP}$ & +6 & -0.3 & +21 & +5 & +20 & +28 & +90 \\
\hline A_MN & -33 & +18 & -60 & -31 & +33 & +64 & -38 \\
\hline
\end{tabular}

Table 2. Percentage of change of three metrics in each UST between 1985 and 2015. \%=percentage of participation in the whole study area; $\mathrm{NP}=$ number of patches; $\mathrm{A} \_\mathrm{MN}=$ patch mean area.

\section{CONCLUSIONS}

Santiago's expansion of urban areas has marked the structure and distribution of USTs, accentuating social segregation in within the city. Thus, it is observed that from the centre there are two concentric zones where predominant USTs have a higher intensity of urbanisation. The peripheral edge of the city was very dynamic, which was significantly modified by the composition and configuration of USTs. This involves the change from structures with a medium and large proportion of open spaces to disperse patches with more complex and smaller shapes (scattered and slightly more complex morphology). Based on the analysis of a set of metrics, we believe that such metrics can be used to understand the city dynamics better and support sustainable planning.

\section{ACKNOWLEDGEMENTS}

We would like to thank FONDECYT 1140319 "Vegetation knowledge based indicators for urban sustainable planning" for funding all research costs.

\section{REFERENCES}

Böhm, P., 1998. Urban Structural Units as a Key Indicator for Monitoring and Optimising the Urban Environment. In: Urban Ecology, Breuste, J., Feldman J. and Uhlman, O. (Eds.). Springer, $714 \mathrm{p}$.

Forman, R. T. and Godron, M., 1986. Landscape Ecology. John Wiley \& Sons, New York. 619 p.

McGarigal, K., Cushman, S.A. and Ene, E., 2012. FRAGSTATS v4: Spatial Pattern Analysis Program for Categorical and Continuous Maps. Computer software program produced by the authors at the University of Massachusetts, Amherst. http://www.umass.edu/landeco/research/fragstats/ fragstats.html (20 March 2016).

Peterman, A., 2006. ¿Quién extendió a Santiago? Una breve historia del límite urbano, 1953-1994. Chapeter in: Santiago, Dónde Estamos y Hacia Dónde Vamos, Galetovic, A. (Ed.). Centro de Estudios Públicos, Santiago, Chile.

Ridd, M.K., 1995. Exploring a V-I-S (vegetation-impervious surface-soil) model for urban ecosystem analysis through remote sensing: comparative anatomy for cities. Int. J. Remote Sensing, Vol. 16, No. 12, 2165-2185.

Rojas, Q., Salgado G., Pino, V. and Carles, J., 2011. Medidas para la Valoración de la Sostenibilidad de los Territorios Metropolitanos: Aplicación al Área Metropolitana de Concepción (Chile). Boletín de la Asociación de Geógrafos Españoles. (55): 81-99.

Romero, H. and Ordenes, F., 2004. Emerging Urbanization in the Southern Andes. Environmental impacts of Urban Sprawl in Santiago de Chile on the Andean Piedmont. Mountain Research and Development (24) 3: 197-201.

Romero, H., Ordenes, F. and Vásquez, A., 2003. Ordenamiento territorial y desarrollo sustentable a escala regional, ciudad de Santiago y ciudades intermedias de Chile. In: Figueroa, E. and Simonetti, J.A. (Eds.). Globalización y Biodiversidad: Oportunidades y desafíos para la sociedad chilena. Editorial Universitaria. pp: 167-207.

Rueda, S., 1999. Modelos e Indicadores para ciudades más sostenibles. Chaper in: Taller sobre Indicadores de Huella y Calidad Ambiental Urbana. Marzo de 1999. Fundació Fòrumambiental, Departament de Medi Ambient de la Generalitat de Catalunya y Agencia Europea de Medio Ambiente. pp. 38p. 
Tyler, M.E., Perks, W.T., 1998. A normative model for urban ecology practice: Establishing performance propositions for ecological planning and design. In: Breuste, J., Feldmann, H. and Uhlmann, O. (Eds.). Urban Ecology. Springer-Verlag. pp. 228-232.

United Nations (UN), 2014. World Urbanization Prospects: 2014 Revision. Department of Economic and Social Affairs, Population Division.
Urban, D., O'Neill, L. and Shugart, H. 1987. Landscape ecology: A hierarchical perspective can help scientist understand spatial patterns. BioScience 37:119-127. 